University of Nebraska - Lincoln

DigitalCommons@University of Nebraska - Lincoln

$5-1988$

\title{
Alternation of Sex Ratio in a Partially Bivoltine Bee., Megachile rotundata (Hymenoptera: Megachilidae)
}

\author{
V. J. Tepedino \\ USDA-ARS \\ F. D. Parker \\ USDA-ARS
}

Follow this and additional works at: https://digitalcommons.unl.edu/entomologyother

Part of the Entomology Commons

Tepedino, V. J. and Parker, F. D., "Alternation of Sex Ratio in a Partially Bivoltine Bee., Megachile rotundata (Hymenoptera: Megachilidae)" (1988). Entomology Papers from Other Sources. 67.

https://digitalcommons.unl.edu/entomologyother/67

This Article is brought to you for free and open access by the Entomology Collections, Miscellaneous at DigitalCommons@University of Nebraska - Lincoln. It has been accepted for inclusion in Entomology Papers from Other Sources by an authorized administrator of DigitalCommons@University of Nebraska - Lincoln. 


\title{
Alternation of Sex Ratio in a Partially Bivoltine Bee, Megachile rotundata (Hymenoptera: Megachilidae)
}

\author{
V. J. TEPEDINO AND F. D. PARKER ${ }^{1}$
}

Bee Biology and Systematics Laboratory, USDA-ARS,

Utah State University, Logan, Utah 84322

\begin{abstract}
Ann. Entomol. Soc. Am. 81(3): 467-476 (1988)
ABSTRACT Data on offspring production by the alfalfa leafcutting bee, Megachile rotundata $(\mathrm{F}$.), from three site-years were used to examine predictions of parental investment and sex ratio theory. In northern Utah, spring-emergent adults produce two types of offspring: those that develop directly to the adult stage and emerge in midsummer, and those that develop to the prepupal stage and enter diapause until the following year. For species with this kind of life cycle, it has been hypothesized that spring parents should bias their investment in summer emergent progeny towards females if spring males survive to participate in the summer mating. Results from all site-years support the theory. The sex ratio of summeremergent progeny is always biased towards females, that of diapausing progeny is usually biased towards males, and there is always a significant difference between the two; and there is no difference in the sex ratio of diapausing offspring, whether produced by the spring or summer generations. However, the main premise of the theory remains unsubstantiated: in a preliminary estimate, we found the probability that spring males participate in summer matings to be very low. The import of the unexpected finding that diapausing progeny are $50 \%$ larger than summer-emergent progeny is discussed.
\end{abstract}

KEY WORDS Insecta, size, diapause, parental investment

Pollination OF Alfalfa (Medicago sativa L.) in Canada and the northwestern United States is accomplished mainly by the semidomesticated alfalfa leafcutting bee, Megachile rotundata $(\mathrm{F}$.) (ALCB). To synchronize adult ALCB emergence with alfalfa flowering in late June and early July, overwintering prepupae are incubated at $30^{\circ} \mathrm{C}$ beginning about 3 wk before peak bloom. Females mate soon after emerging and begin to construct nests in holes in artificial domiciles placed in the fields. For the remaining weeks of their adult lives, they provision the cells in these nests with pollen and nectar collected from alfalfa flowers, lay an egg on each completed provision, and seal the cell with masticated leaf pieces (Klostermeyer 1982). Each female typically produces several nests with several progeny in each (V.J.T., unpublished data).

The ALCB exhibits a partially bivoltine life cycle that sometimes complicates its management by those who use it to pollinate alfalfa. Under partial bivoltinism, a variable proportion of progeny of spring adults (occasionally more than $50.0 \%$ ) forego diapause and emerge as adults from late July to September. Remaining progeny of the spring generation and all progeny of the summer-emergent generation enter a prepupal diapause and do not emerge as adults until the following spring.

The emergence of a partial second generation diminishes the number of bees available for pollination in the ensuing year in at least two ways.

${ }^{1}$ USDA-ARS Screwworm Research, American Embassy, Costa Rica, PSC Box 496, APO Miami 34020
First, because alfalfa is past peak bloom when summer emergence begins, bees either leave the fields in search of more abundant forage, or they remain and produce relatively few offspring (Parker \& Tepedino 1982). Second, emerging bees destroy some of their nonemergent siblings when they leave the nest (Tepedino \& Frohlich 1984). Although some workers report success in reducing secondgeneration emergence in Canada through appropriate temperature treatments of immature stages (Richards 1984), others find voltinism of immatures unresponsive to temperature or photoperiodic treatments (Johansen \& Eves 1973, Tasei 1975, Bitner 1976, Tasei \& Masure 1978, Parker \& Tepedino 1982, Tepedino \& Parker 1986). Present evidence suggests that diapause is maternally controlled.

The partially bivoltine life cycle is also of interest because of theoretical predictions that link it with exceptional sex allocation patterns. In panmictic populations with either discrete or completely overlapping generations, it is usual for parents to apportion their reproductive investment equally between sons and daughters (Fisher 1930, Charnov 1982). Thus, the primary sex ratio in each generation should be the inverse of the cost ratio of an average son and daughter. However, sex allocation patterns may be very different when the sexes differ in their overlap with the next generation. Seger (1983), J. W. Stubblefield (personal correspondence), and Stubblefield \& Charnov (1986), building on theoretical work of Werren \& Charnov (1978), have examined the case in which some spring-emergent males increase their reproductive 
value (Grafen 1986) by mating with females of their own generation and of the succeeding partial summer generation. (For a detailed and particularly lucid development, see Grafen 1986.) The higher is $S$, the probability that spring males survive to inseminate summer females, the less valuable is a summer male, because summer-emergent males must compete with surviving spring males for summer-emergent female mates. In contrast, spring-emergent females mate only with coemerging males and most of them are dead when the summer generation begins to emerge. Under such circumstances, the reproductive value of spring females is increased if they produce more females and fewer males than expected among their summer-emergent progeny and more males and fewer females among their progeny that will enter diapause and emerge the following spring. In the terminology of Seger (1983): the fraction of summeremergent individuals that are males $\left(m_{1}\right)$ should be significantly less than the fraction of overwintering individuals that are males $\left(m_{2}\right)$, and the sex ratio of the population can be said to alternate. Two objectives of this report are to test this prediction and to supply an approximation of $S$, using original data and information in the literature.

Another important parameter of Seger's (1983) model is $T$, the proportion of all overwintering bees that were produced by spring parents. When $T:=$ 1 , the population is univoltine and there is no alternation of sex ratio; when $T=0$, there are at least two generations per year. Alternation of sex ratio is expected if $1>T>0$ and $S>0$. Our third objective is to estimate the value of $T$ indirectly by examining Seger's (1983) implicit assumption (J. W. Stubblefield, personal correspondence) that $T=T_{\mathrm{m}}=T_{\mathrm{f}}$, in which $T_{m}$ and $T_{\mathrm{f}}$ are the fraction of all overwintering males or females, respectively, that were produced by spring parents.

\section{Materials and Methods}

Data were collected from two sites in 1981. At North Logan, Utah (NL81), bees were incubated in the laboratory at $29^{\circ} \mathrm{C}$ and transferred to a commercial carrot (Daucus carota L.) field when emergence began. A nesting domicile of several thousand vacant holes, each containing a paper soda straw (67 mm length, $5 \mathrm{~mm}$ inside diameter), was provided for nesting (see Tepedino 1983 for further details). All straws with completed nests were collected every few days and opened in the laboratory. Cells in their leaf sheaths were individually inserted into gelatin capsules and maintained at room temperature $\left(24-28^{\circ} \mathrm{C}\right)$ and illumination (15-16 h light) in Petri dishes. The sex of the emerging bees was recorded, and most were released at the field plot. Bees that entered diapause were stored at 4$5^{\circ} \mathrm{C}$ in the fall and were incubated at $29^{\circ} \mathrm{C}$ in June 1982 , when the number and sex of emerging adults was recorded.
Table 1. 1981 NL site. Number of male and female progeny that emerged in midsummer (second generation) versus those that entered diapause, by date of nest collection

\begin{tabular}{|c|c|c|c|c|c|c|c|}
\hline \multirow{2}{*}{$W k$} & \multirow{2}{*}{$\begin{array}{l}\text { Collection } \\
\text { date }\end{array}$} & \multicolumn{3}{|c|}{ Emerged midsummer } & \multicolumn{3}{|c|}{ Entered diapause } \\
\hline & & $\delta \delta$ & 99 & $\%$ む & sôे & $\$$ & $\% \$ 0$ \\
\hline 1 & 17 July & 170 & 187 & 47.6 & 2 & 3 & 40.0 \\
\hline 2 & 20 July & 478 & 449 & 51.6 & 17 & 21 & 44.7 \\
\hline 3 & 23 July & 461 & 868 & 34.7 & 127 & 126 & 50.2 \\
\hline 4 & 27 July & 688 & 1,117 & 38.1 & 460 & 339 & 57.6 \\
\hline 5 & 30 July & 209 & 775 & 21.2 & 441 & 262 & 62.7 \\
\hline 6 & 10 Aug. ${ }^{a}$ & 70 & 373 & 15.8 & 1,392 & 764 & 64.6 \\
\hline \multicolumn{2}{|c|}{ Total } & 2,076 & 3,769 & 35.5 & 2,439 & 1,515 & 61.7 \\
\hline
\end{tabular}

${ }^{a}$ Not all nests collected were monitored.

The second site was a commercial alfalfa field at Clarkston, Utah (CL81), approximately $32 \mathrm{~km}$ northwest of the carrot field. Bees released here were drawn from the same population as those released at NL81. Their treatment was identical in all respects, except that two diameters of straws were provided (inside diameters of 4 and $5 \mathrm{~mm}$, $67 \mathrm{~mm}$ length) and a random sample of adult bees was weighed $\left(\mathrm{mg}^{-1}\right)$ when they emerged either in midsummer or in the following year. In 1983, we gathered additional data at this site (CL83) using only 5 -mm nests and without repeating the weighing part of the study (see Parker 1985 for details). Other methodological and statistical details are described below under the appropriate site-year.

Voucher specimens have been deposited in the G. E. Bohart Aculeate Collection (USDA) at Utah State University, Logan.

\section{Results}

1981 NL. Bees began nesting during the second week of July and continued to nest into September. Although released in the carrot field, they foraged almost exclusively on more distant alfalfa fields (Tepedino 1983). We collected nests through 10 August, the last date that we could be sure they were the products of the spring generation. Second generation emergence began during the second week of August and continued into early September. Offspring produced by the summer-emergent generation were not monitored.

As predicted by Seger (1983), Stubblefield (personal correspondence), and Stubblefield \& Charnov (1986), the sex ratio of emergent second-generation bees was strongly biased toward females and the sex ratio of diapausing bees was strongly biased toward males (Table 1): only $35.5 \%$ of second generation bees were males compared with $61.7 \%$ of those that entered diapause $\left(\chi^{2}=650.0, P \ll 0.001\right)$. This intergeneration difference in sex ratio resulted from the tendency of males to enter diapause earlier than females. Fig. 1 shows the weekly percentage of male offspring, and the percentage of all males and females that entered diapause. The percentage of male offspring fluctuated from 37.2 


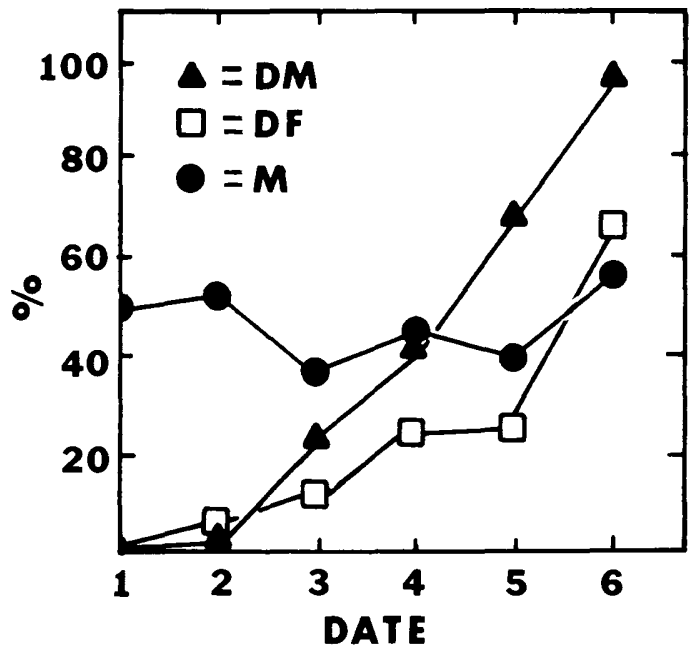

Fig. 1. 1981 NL. Percentage of all male (DM) and female (DF) progeny that entered diapause; and percentage of all offspring that were males $(\mathrm{M})$ by nest collection date. Dates correspond to those in Table 1.

to $56.3 \%$ and lacked an obvious pattern. In contrast, the percentage of males and females entering diapause increased steadily from the first to the last collection date, but the percentage of males was almost always significantly higher. All comparisons between numbers of emerging and diapausing males and females by week were significant $\left(\chi^{2}\right.$ tests, all $P \ll 0.001$ ) except for the 17-20 July collection dates $(P>0.25)$. The overall pattern of increasing percentage of offspring entering dia- pause with season has been reported previously (Krunic 1972, Johansen \& Eves 1973, Parker 1985).

1981 CL. To achieve synchrony with alfalfa bloom, bees were incubated and transported to the field $10 \mathrm{~d}$ earlier than at NL81. Completed nests were first noted and collected on 6 July. To simplify presentation and analysis, all collections made within each week have been combined. Collections continued until 1 October, when nesting was completed, but the activity was reduced after the week of 2 September. All of the collected nests were monitored for number and sex of summer-emergent bees. We opened a subsample of these nests, and placed the cells in gelatin capsules to store diapausing individuals during the winter and for incubation the following spring. In Table 2, we show the number of diapausing individuals as adjusted for the unequal sampling effort among weeks. All of the statistical tests cited below, however, are based on unadjusted data from nests actually examined. The results from 4- and 5-mm-diameter straws were in close agreement, except that the percentage of males was consistently higher in $4-\mathrm{mm}$ than in 5-mm straws. Therefore, we report only on 5 -mm nests.

Nests could be separated into three groups according to the parental generation. We could confidently assign parentage of nests completed through week 5 (11 August) to the spring generation, because the summer generation did not begin to emerge until 6 August. Nests completed during weeks 6 and 7 constitute a second group that contained progeny of both spring- and summer-emergent females. Although ALCB females live for a

Table 2. 1981 CL. Number of male and female progeny that emerged in midsummer versus those that entered diapause, by date of nest collection and parentage

\begin{tabular}{|c|c|c|c|c|c|c|c|c|c|}
\hline \multirow{2}{*}{$W k$} & \multirow{2}{*}{$\begin{array}{l}\text { Collection } \\
\text { date }\end{array}$} & \multirow{2}{*}{$\begin{array}{c}\text { Nests } \\
\text { collected }\end{array}$} & \multirow{2}{*}{$\begin{array}{c}\text { Nests } \\
\text { examined }\end{array}$} & \multicolumn{3}{|c|}{$\begin{array}{l}\text { Emerged } \\
\text { midsummer }\end{array}$} & \multicolumn{3}{|c|}{ Entered diapause $^{a}$} \\
\hline & & & & ơే & कq & $\%$ ठ̊̊̊ & $\delta \hat{o ̂ t ~}$ & 89 & \% ช̊̂ิ \\
\hline 2 & 21 July & 1,118 & 400 & 103 & 207 & 33.2 & 1,272 & 500 & 71.8 \\
\hline 3 & 29 July & 988 & 402 & 37 & 120 & 23.6 & 892 & 231 & 79.4 \\
\hline 4 & 5 Aug. & 843 & 400 & $0^{b}$ & $0^{b}$ & - & 1,016 & 272 & 78.9 \\
\hline 6 & $18 \mathrm{Aug}$. & 541 & 376 & - & - & - & 914 & 246 & 78.8 \\
\hline 7 & 25 Aug. & 452 & 372 & - & - & - & 796 & 239 & 76.9 \\
\hline \multicolumn{2}{|c|}{ Subtotal ${ }^{d}$ wk 6-7 } & .993 & 748 & - & - & - & 1,710 & 485 & 77.9 \\
\hline 8 & 2 Sept. & 195 & 195 & - & - & - & 261 & 80 & 76.5 \\
\hline 9 & 9 Sept. & 68 & 68 & - & - & - & 151 & 49 & 75.5 \\
\hline \multicolumn{2}{|l|}{ Total } & 5,405 & 2,992 & 435 & 554 & 44.0 & 6,517 & 1,903 & 77.4 \\
\hline
\end{tabular}

a Number of diapausing males and females have been adjusted to account for unequal sampling effort among weeks by multiplying actual number emerged by the number of nests collected/nests examined.

${ }^{b}$ No bees emerged from nests collected after 29 July.

${ }^{c}$ Progeny of weeks 1-5 are products of spring generation only.

${ }^{d}$ Progeny of weeks 6-7 are products of both spring and summer emergent generations

${ }^{e}$ Progeny of weeks 8-11 are products of summer emergent generation. 


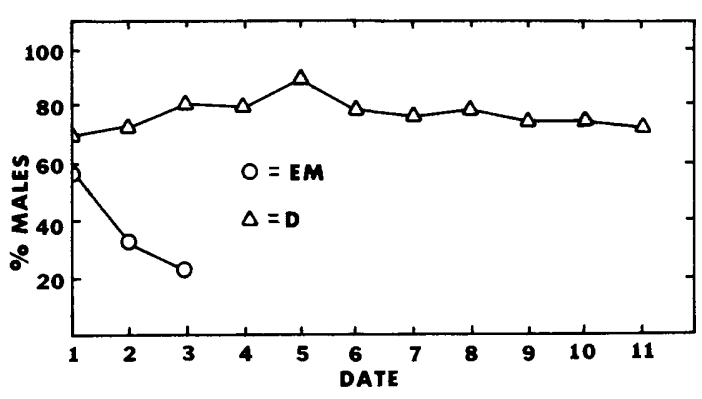

Fig. 2. 1981 CL. Percentage of all progeny entering diapause (D) or emerging in summer (EM) that were males by nest collection date. Dates correspond to those in Table 2 .

maximum of $6 \mathrm{wk}$ (Tirgari 1963), spring emergence extends over a period of 2 to $3 \mathrm{wk}$. Because emergence began in early July, a few spring females would still be nesting through week 7 . However, the percentage of total progeny produced by spring-emergent bees during this period should be relatively low, particularly for week 7 . The third group (weeks 8-11) contains progeny produced only by the summer-emergent generation. Our productivity estimate for this group is incomplete for several reasons: not all bees that emerged in the laboratory could be released at the site; there is no assurance that those released actually nested at the site; and there may have been some migration into the site by summer-emergent bees from other nesting sites nearby. Thus, intergeneration comparisons of productivity are inappropriate.

Mortality of immature bees sometimes exceeded $65 \%$ because of an epizoötic of chalkbrood, a disease caused by the ascomycete Ascosphaera aggregata Skou (McManus \& Youssef 1984, Parker 1985). Nevertheless, the sex ratio and emergence patterns (Table 2) generally agreed with those found for NL81, in which mortality was much lower. First, most summer-emergent individuals were females $(56.0 \%)$, whereas males again predominated among progeny that entered diapause (weeks 1-5, $77.5 \%)$. The difference in sex ratio between the groups was highly significant $\left(\chi^{2}=334.1, P \ll\right.$ $0.001)$. Second, seasonal transitions were again evident. As the season progressed, a steadily decreasing percentage of summer-emergent bees were males (Fig. 2) $\left(\chi^{2}=74.4\right.$, df $=2, P \ll 0.001$; week $1>$ weeks $2,3, P \ll 0.001$; week $2>3, P<0.05$ ). Third, the proportion of all bees entering diapause steadily increased with season $\left(\chi^{2}=477.1, \mathrm{df}=3\right.$; week $4>3>2>1$; $\chi^{2}$ tests, all $\left.P<0.001\right)$. And fourth, males again tended to precede females in entering diapause (Fig. 3). All weekly comparisons of emerging and diapausing males and females were significantly different $\left(\chi^{2}\right.$ tests weeks $1-3$, all $P<0.001)$ : a consistently greater proportion of males than females entered diapause.

The results from CL81 differed from those at NL81 in two important ways. First, the percentage of male progeny produced by the spring generation

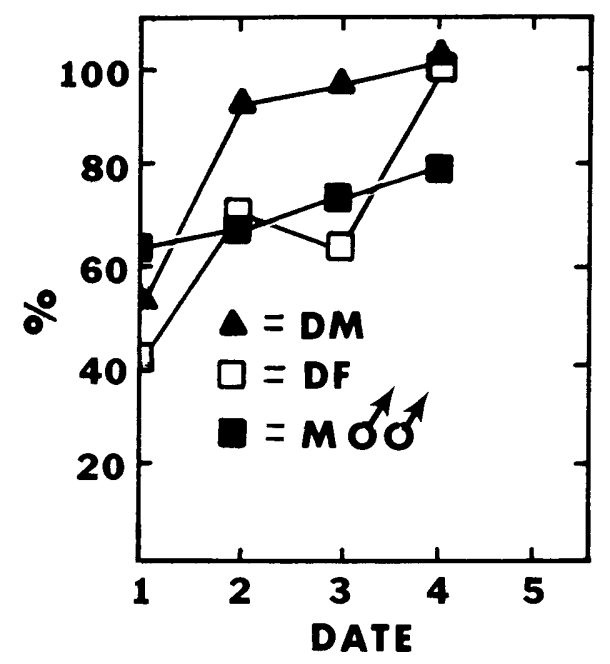

Fig. 3. 1981 CL. Percentage of all spring generation progeny that were males $(\mathrm{M})$; and percentage of all males (DM) and females (DF) that entered diapause by nest collection date. Dates correspond to those in Table 2.

was much higher at CL81 ( $72.4 \%$, weeks $1-5$ only) than at NL81 (46.1\%). The sex ratio of spring generation progeny at CL81 was strongly biased toward males (2.62:1, male/female) and was significantly different from the expected value $\left(\chi^{2}=\right.$ $525.9, P \ll 0.001$, weeks $1-5)$. A second important difference was in the percentage of emergent progeny. At NL81, 59.6\% of spring generation progeny emerged in midsummer, but at CL81 only $15.5 \%$ of those produced during weeks $1-5$ did so. It is likely that these differences are interrelated; the strongly biased male sex ratio at CL81 would lead to a lower percentage of emergence because a greater proportion of males tend to enter diapause. These differences are puzzling, however, because the spring generation bees released at both sites were drawn from the same population. The only difference in treatment was the earlier release of CL81 bees than of NL81 bees.

Weight data were analyzed by unbalanced threeway factorial ANOVA with sex, emergence category, and week of nest collection as factors. Overall mean weights of all male and female progeny were used to calculate the expected sex ratio of $1: 14$ (male/female) for the population (Torchio \& Tepedino 1980). Several pertinent patterns emerged from this analysis (Table 3 ). All three factors were significant $(P \ll 0.001)$; females were heavier than males; and overwintering bees were heavier than emergent bees.

Variation among weeks was more complicated. Among overwintering bees, males and females produced by the spring generation (weeks 1-5) were considerably heavier than those produced by the summer generation (weeks 8-11). Progeny produced by both generations during weeks $6-7$ were intermediate in weight for both sexes. In addition, a significant $(P=0.002)$ interaction of sex with 
Table 3. Mean of live weights $\left(\mathrm{mg}^{-1}\right)$ of adult ALCBs upon emergence in midsummer or the following spring. Bees from weeks 5 and 10 are not weighed ${ }^{a}$

\begin{tabular}{|c|c|c|c|c|c|c|c|c|c|c|c|c|}
\hline \multirow{3}{*}{$W k$} & \multicolumn{6}{|c|}{ Emerged midsummer } & \multicolumn{6}{|c|}{ Entered diapause } \\
\hline & \multicolumn{3}{|c|}{$\delta \hat{\jmath}$} & \multicolumn{3}{|c|}{99} & \multicolumn{3}{|c|}{ రిశ } & \multicolumn{3}{|c|}{ १९ } \\
\hline & $n$ & $\bar{x}$ & $\mathrm{SD}$ & $n$ & $\bar{x}$ & SD & $n$ & $\bar{x}$ & SD & $n$ & $\bar{x}$ & SD \\
\hline 1 & 294 & 26.2 & 3.7 & 227 & 33.8 & 5.1 & 23 & 42.2 & 5.9 & 10 & 46.8 & 6.2 \\
\hline 2 & 22 & 26.5 & 4.2 & 60 & 34.7 & 6.1 & 68 & 44.1 & 5.5 & 35 & 51.2 & 6.9 \\
\hline 3 & 15 & 26.9 & 4.3 & 43 & 31.2 & 6.3 & 80 & 40.3 & 6.0 & 25 & 48.6 & 6.1 \\
\hline 4 & - & - & - & - & - & - & 35 & 39.3 & 4.9 & 11 & 47.6 & 7.2 \\
\hline subtotal wk $1-5$ & - & $26.3^{b}$ & - & - & $33.6^{b}$ & - & - & $41.6^{b}$ & - & - & $49.2^{b}$ & - \\
\hline 6 & - & - & - & - & - & - & 60 & 40.0 & 5.5 & 16 & 47.3 & 10.8 \\
\hline 7 & - & - & - & 一 & - & - & 56 & 36.4 & 5.4 & 18 & 44.9 & 8.8 \\
\hline Subtotal wk 6-7 & & & & & & & - & $38.3^{b}$ & - & - & $46.1^{b}$ & - \\
\hline 8 & - & - & - & 一 & - & - & 57 & 35.8 & 6.3 & 18 & 45.6 & 5.6 \\
\hline 9 & - & - & - & - & - & - & 69 & 34.6 & 4.9 & 20 & 46.3 & 6.3 \\
\hline 11 & 一 & - & - & - & - & - & 21 & 36.7 & 3.0 & 10 & 40.8 & 4.5 \\
\hline Subtotal wk 8-11 & 一 & - & 一 & - & - & - & - & $35.7^{b}$ & - & - & $44.6^{b}$ & - \\
\hline Total & & $26.3^{b}$ & & & $33.6^{b}$ & & - & $40.3^{b c}$ & - & - & $48.0^{b c}$ & - \\
\hline Grand mean $^{d}$ & & 39.4 & & & 44.8 & & & & & & & \\
\hline
\end{tabular}

$n$, number weighed; SD, standard deviation.

"Because bees were not weighed in proportion to their occurrence by week or by emergence period, means for subtotals and totals have been weighed according to relative abundances of each sex.

In calculating adjusted weights, abundances of males and females of week 5 have been included in subtotals for weeks 1-5, and abundances of males and females from week 10 have been included in subtotals for weeks 8-11.

${ }^{d}$ Weighted mean of both midsummer emergent and diapausing bees.

emergence category signified a difference in the ratio of female to male size between emergent and overwintering individuals: among emergent bees, females were relatively larger than males (ratio 1.28) as compared with overwintering bees (ratio 1.19).

1983 CL. Results for CL83 corroborate those presented previously and, therefore, are treated briefly (Table 4). Summer-emergent bees were strongly biased toward females $(72.1 \%)$, and the sex ratio was significantly different from what we expected $(P \ll 0.001)$. The percentage of males among emergent bees declined with the season. The sex ratio of bees that entered diapause was biased toward males. The sex ratio of diapausing bees was indistinguishable from that expected

Table 4. 1983 CL. Numbers and percentages of progeny that emerged in midsummer or entered diapause. Sampling effort varied among weeks and between emergence categories

\begin{tabular}{|c|c|c|c|c|c|c|c|}
\hline \multirow{2}{*}{$\begin{array}{c}\text { Date } \\
\text { collected }\end{array}$} & \multicolumn{4}{|c|}{ Emerged midsummer } & \multicolumn{3}{|c|}{ Entered diapause } \\
\hline & $\%$ total & 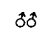 & \% & $\%$ ơ & ¿ôे & ९९ & $\%$ ôे \\
\hline 22 July & 82.1 & 165 & 277 & 37.3 & $\complement^{a}$ & $-^{a}$ & - \\
\hline 29 July & 55.0 & 247 & 699 & 26.1 & $-^{a}$ & $\simeq^{a}$ & - \\
\hline 5 Aug. & 14.5 & 254 & 643 & 28.3 & 103 & 74 & 58.2 \\
\hline 12 Aug. & 5.8 & 59 & 248 & 19.2 & 105 & 72 & 59.3 \\
\hline 19 Aug. & 3.9 & 2 & 10 & 16.7 & 133 & 106 & 55.6 \\
\hline 26 Aug. & 0.9 & 1 & 5 & 16.7 & 120 & 90 & 57.1 \\
\hline 2 Sept. & 0.0 & 0 & 0 & - & 115 & 138 & 45.5 \\
\hline 9 Sept. & 0.0 & 0 & 0 & - & 49 & 37 & 57.0 \\
\hline 16 Sept. & 0.0 & 0 & 0 & - & 25 & 38 & 39.7 \\
\hline Totals & $21.7^{b}$ & 728 & 1,882 & 27.9 & 650 & 555 & 53.9 \\
\hline
\end{tabular}

${ }^{a}$ No sample examined.

${ }^{b}$ Calculated on cells examined through 26 August only.
$(P>0.50)$ but was significantly different from that of summer-emergent bees $(P \ll 0.001)$.

Estimating $m_{1}, m_{2}$, and T. To estimate the proportion of investment in summer-emergent individuals that was committed to males $\left(m_{1}\right)$, and the proportion of investment in diapausing offspring (made by both spring- and summer-emergent parents) that was made in males $\left(m_{z}\right)$, it was first necessary to adjust the abundance data to account for differences in size (investment) between an average male and female (Seger 1983). Total investment by spring- and summer-emergent adults in male and female progeny that either emerged in summer or entered diapause was calculated using the data on average weights and numbers of individuals from Tables 1-4. Because bees from NL81 and CL83 were not weighed, we used the average weights of each sex for each period at CL81 to estimate investment in progeny at these sites. For example, at NL81, $m_{1}$ was calculated as $(2,076$ ठิ̊े $\times 26.3 \mathrm{mg}) /[(2,076$ ô 0 $\times 26.3 \mathrm{mg})+(3,769$ 우 $\times$ $33.6 \mathrm{mg})$ - - that is, the number of males that emerged in summer (Table 1) times their average weight divided by the number of emergent males and females times their respective weights at CL81 (Table 3). For comparison, and because of unequal sampling effort at CL81 (see above), we also provide separate estimates of $m_{2}$ for progeny of spring and summer generations.

Although estimates of $m_{1}$ and $m_{2}$ (Table 5) showed considerable variability among site-years, as predicted by Seger (1983) and J. W. Stubblefield (personal communication), the value of $m_{2}$ was consistently larger than that of $m_{1}$. Indeed, $m_{2}$ was approximately twice $m_{1}$ in all comparisons. In ad- 
Table 5. Estimates of the proportion of investment in males among summer emergent $\left(m_{1}\right)$ or diapausing $\left(m_{2}\right)$ progeny by spring (SP) and summer emergent (SE) parents $^{a}$

\begin{tabular}{lccccc}
\hline \hline \multicolumn{1}{c}{ Site } & $m_{1}$ & $m_{2}(\mathrm{SP})$ & $\begin{array}{c}m_{2} \text { (SP } \\
\text { and SE) }\end{array}$ & $m_{2}(\mathrm{SE})$ & $\Sigma m_{2}$ \\
\hline $\mathrm{CL81}$ & 0.381 & 0.744 & 0.745 & 0.708 & 0.742 \\
$\mathrm{NL81}^{b}$ & 0.301 & 0.576 & - & - & - \\
$\mathrm{CL83}^{b}$ & 0.232 & - & - & - & 0.496 \\
\hline
\end{tabular}

${ }^{a}$ (SP and SE) represents estimate for progeny produced during weeks 6 and 7 at CL81 only; $\Sigma m_{2}$ represents estimate for diapausing progeny of both generations.

${ }^{b}$ Average weights for corresponding periods at CL81 used to estimate investment.

dition, spring- and summer-emergent parents produced a similar proportion of males among overwintering progeny.

We also estimated Seger's (1983) parameter $T$, the proportion of all overwintering bees produced by the spring generation. We could not directly estimate $T$ at CL81, because we could not be sure of the parentage of progeny produced during weeks 6 and 7 , and because the productivity of the summer generation was almost certainly underestimated. Instead, we estimated $T$ as $T_{\mathrm{m}}=T_{\mathrm{f}}=T$, in which $T_{\mathrm{m}}$ and $T_{\mathrm{f}}$ are the proportion of all overwintering males or females, respectively.

Values of $T_{\mathrm{m}}$ and $T_{\mathrm{f}}$ were calculated for CL81 under several alternative assumptions. Because of the uncertainty of parentage during weeks 6 and 7 , we computed values of $T_{\mathrm{m}}$ and $T_{\mathrm{f}}$ in two ways. First, progeny of weeks 1-5 were considered to be products of the spring generation, progeny of weeks 8-11 were products of the summer generation, and progeny of weeks 6 and 7 were excluded. In the second way, we considered progeny of weeks 1-6 as products of the spring generation, and progeny of weeks $7-11$ as products of the summer generation. In addition, the values of $T_{\mathrm{m}}$ and $T_{\mathrm{f}}$ can be calculated using either numbers of individuals or numbers of individuals adjusted by some measure of cost such as weight. Because there is no compelling reason to favor one method of estimation over the other at present (J. Seger \& J. W. Stubblefield, personal communication), we computed both.

Estimates of $T_{\mathrm{m}}$ and $T_{\mathrm{f}}$ were slightly higher when a weighted measure was used; they were also higher when the data from weeks 6 and 7 were excluded (Table 6). However, within any particular assumption, $T_{\mathrm{m}}$ and $T_{\mathrm{f}}$ were essentially equivalent. This finding is important because if $T_{\mathrm{m}} \neq T_{\mathrm{f}}$, then Seger's (1983) model requires modification (J. W. Stubblefield, personal communication). The actual value of $T$ at CL81 was lower than that given here because the productivity of summer parents was underestimated.

Calculating $\boldsymbol{S}$. A critical parameter requiring estimation is Seger's (1983) $S$, the probability of a spring male surviving to fertilize a summer-emergent female. To calculate $S$, estimates of the emergence and survivorship curves of spring males, and
Table 6. Estimates of the proportion of overwintering males $\left(T_{m}\right)$, females $\left(T_{t}\right)$, and both sexes combined $(T)$ made by the spring generation at CL81 under four assumptions: (1) estimate adjusted by the weight (cost) of an average individual; (2) estimate based on number of individuals only; (a) production of spring generation $=$ weeks 1-5, summer generation $=$ weeks $8-11$, weeks 6 7 excluded; (b) production of spring generation $=$ weeks 1-6, summer generation $=$ weeks $7-11$

\begin{tabular}{cccc}
\hline \hline Assumption & $T_{\mathrm{m}}$ & $T_{\mathrm{f}}$ & $T$ \\
\hline la & 0.905 & 0.887 & 0.900 \\
$\mathrm{~b}$ & 0.818 & 0.798 & 0.813 \\
$2 \mathrm{a}$ & 0.891 & 0.877 & 0.888 \\
$\mathrm{~b}$ & 0.797 & 0.783 & 0.794 \\
\hline
\end{tabular}

the emergence curves of second-generation males and females, are required. We have obtained this information from several sources; to calculate the emergence of spring bees by sex, we used data from F.D.P. (unpublished), that compared the numbers of males and females emerging over a period of $18 \mathrm{~d}$ (17 June-4 July) under two treatments. Bees were either subjected to typical storage treatment (held at $5^{\circ} \mathrm{C}$ over winter and incubated at $30^{\circ} \mathrm{C}$ in spring), or kept outdoors through the winter in Logan, Utah, in a small, unheated, screened enclosure and allowed to emerge naturally (Fig. 4). Emergence of bees in the outdoor treatment was less synchronic (more platykurtic) than emergence from the typical storage treatment. Statistical comparisons of treatments by sex showed that differences were highly significant for both sexes $\left(\chi^{2}\right.$ tests, both $P \ll 0.001$ ). In our subsequent calculations, we use the data from the outdoor treatment, because it probably is more indicative of natural emergence.

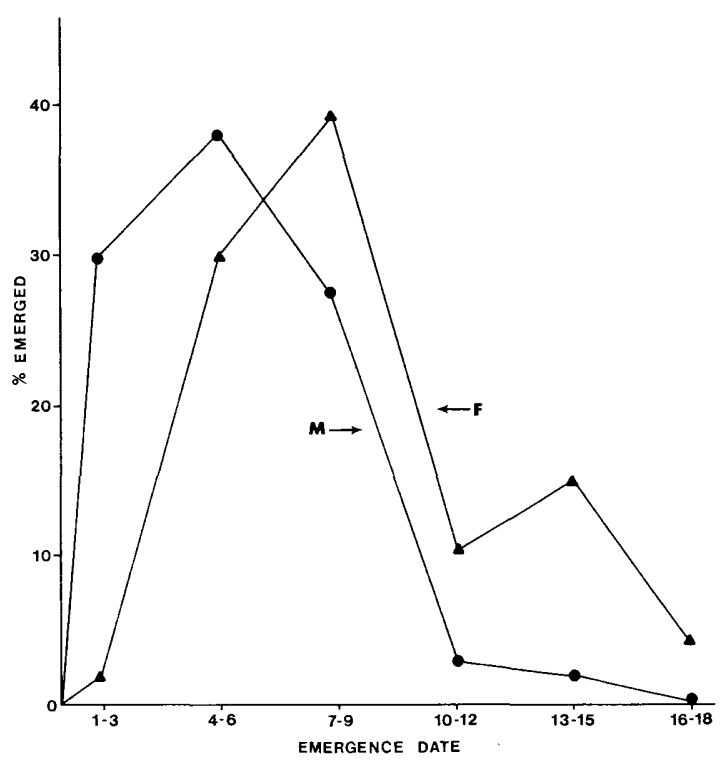

Fig. 4. Natural emergence pattern of male (M) and female $(\mathrm{F})$ leafcutter bees of spring generation. $n(\mathrm{M})=$ 2,$197 ; n(\mathrm{~F})=1,133$. 


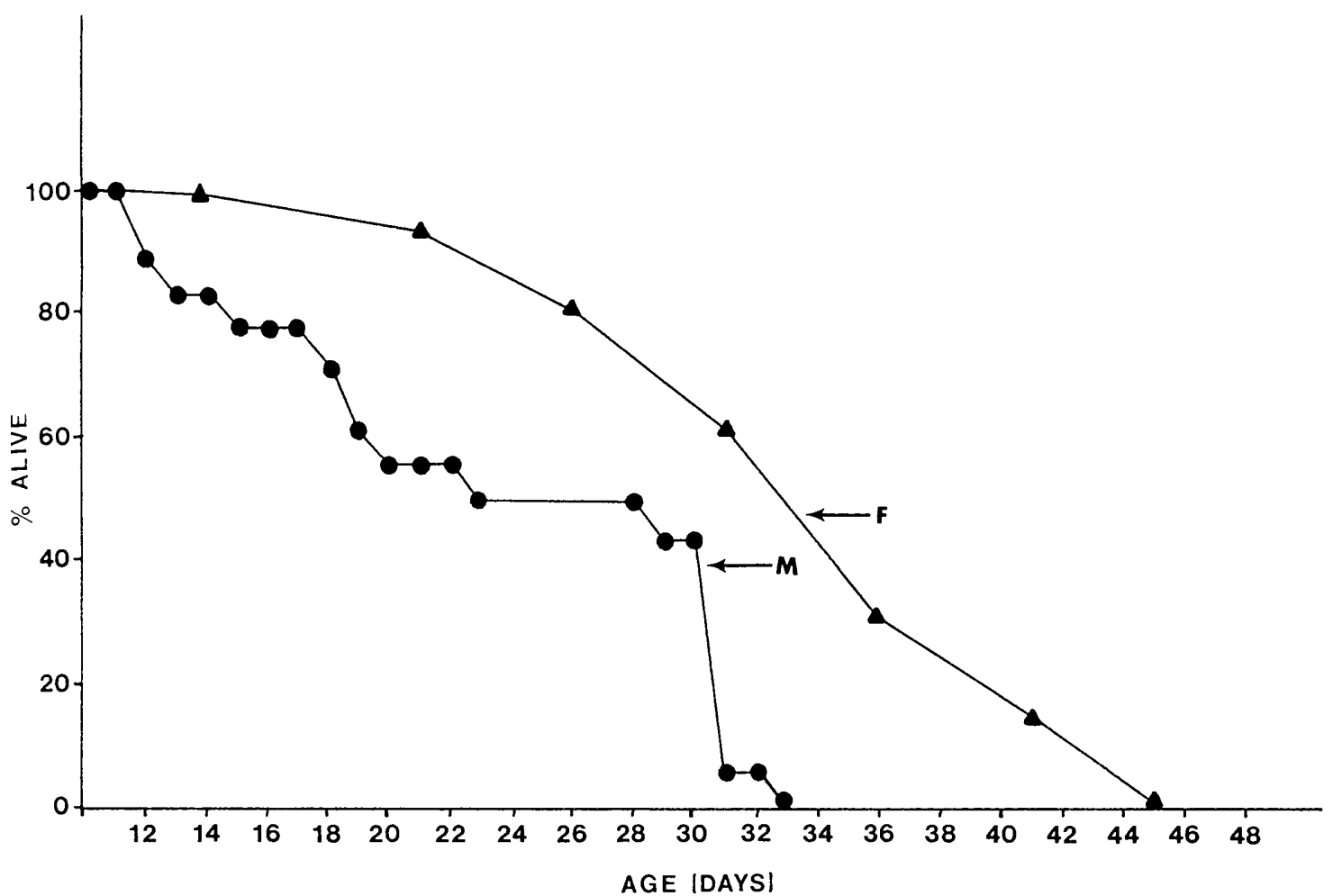

Fig. 5. Survivorship curves for male $(\mathrm{M})$ and female $(\mathrm{F})$ leafcutter bees in a greenhouse (calculated from data in Tirgari 1963). $n(\mathrm{M})=18 ; n(\mathrm{~F})=34$.

Data on longevity of spring-emergent males and females is available from Tirgari (1963), who studied the ALCB under greenhouse conditions, and Richards (1984), who provides information from a field population in southern Alberta. Although Tirgari's (1963) sample sizes are much smaller than Richards's (1984), we have used Tirgari's data to

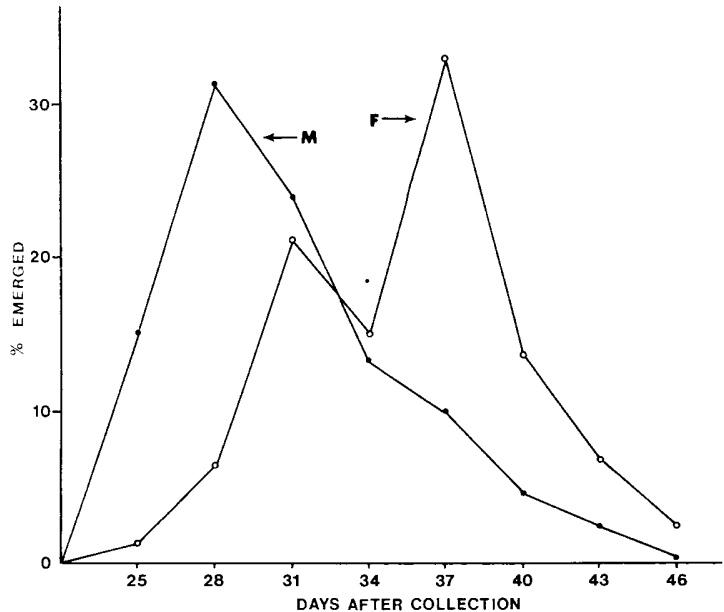

Fig. 6. Emergence pattern of male (M) and female F) leafcutter bees of summer generation. $n(\mathrm{M})=282$; $n(\mathrm{~F})=218$. construct a survivorship curve (Fig. 5) because his information is more precise.

Finally, emergence curves of the summer generation were obtained from our data at CL81; bees were recorded by sex and date of emergence (Fig. $6)$.

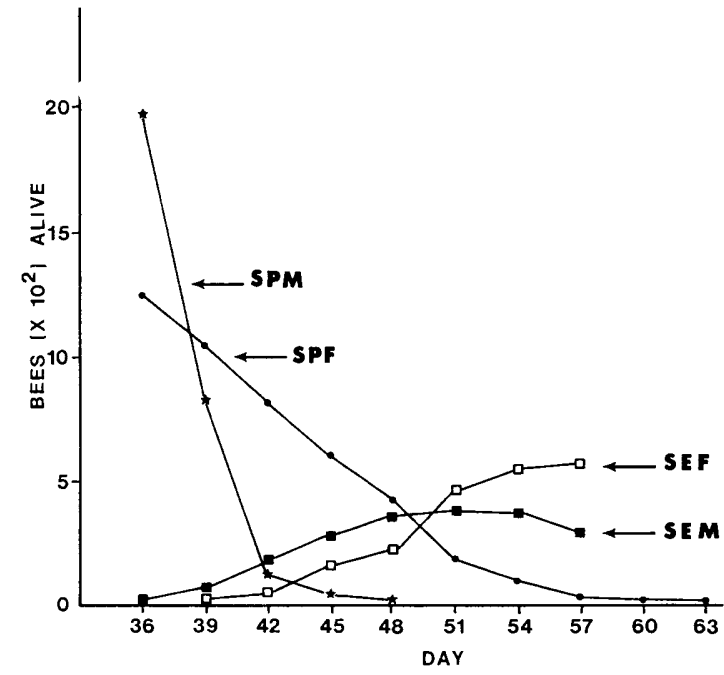

Fig. 7. Hypothetical number of surviving spring males (SPM), spring females (SPF), summer-emergent males (SEM), and summer-emergent females (SEF) by days after initial emergence of spring generation. 
To generate the curves shown in Fig. 7, we applied the emergence and mortality curves (Fig. 4) to a hypothetical population of 6,000 males and 1,600 females. These numbers were chosen as approximations of the number of overwintering bees produced at CL81 (Table 2). The number of summer-emergent males and females was also taken as those produced by the spring generation at CL81 (Table 2). The same estimates were applied to each group of males and females according to its emergence date. As seen in Fig. 7, although spring males appear to survive just long enough to overlap with the second generation, and the ratio of spring to summer males is initially high when summer emergence commences, $S$ appears to be very close to zero because the last of the spring males are dead by the time summer females emerge in any significant numbers.

\section{Discussion}

The sex ratio of successive generations of $M$. rotundata alternated in all three site-years in the manner predicted by Seger (1983) and J. W. Stubblefield (personal communication). There were significantly more females than expected in the summer-emergent generation and significantly more females among summer-emergent bees than among diapausing bees (Tables 1, 2, and 4). In addition, summer-emergent females produced overwintering progeny in approximately the same sex ratio as those produced by spring-emergent females. Limited evidence of alternation of sex ratio in the ALCB has also been reported by Tasei (1975), Parker (1979), and Parker \& Tepedino (1982).

Although the evidence supports the prediction of Seger (1983) and J. W. Stubblefield (unpublished data), their primary premise remains unsubstantiated; available evidence suggests that few springemergent males survive to mate with summeremergent females (Fig. 7)-i.e., the value of $S$ appears to approach zero. There are, however, several reasons to regard this conclusion with circumspection. Survivorship may have been underestimated in Tirgari's (1963) greenhouse study of only 18 spring generation males. Indeed, Richards's (1984) data suggest that average longevity is greater for both sexes in the field. Unfortunately, Richards's (1984) data are not detailed enough to be conclusive. Alternatively, Tirgari's (1963) data may more closely represent maximal rather than minimal longevity, because conditions are generally more benign in a greenhouse than in nature. In the greenhouse, predators and parasites are absent, food and shelter are immediately obtainable, and weather is less variable. The point will remain moot until additional field studies are conducted.

$S$ is also influenced by developmental rates and emergence curves of spring and summer generations; these, in turn, are critically influenced by temperature (Stephen \& Osgood 1965, Krunic \& Hinks 1972, Johansen \& Eves 1973, Tasei 1975,
Rank \& Goerzen 1982, Richards 1984). Thus, it is possible that subtle differences in the temperatures at which immatures were stored and reared among the three studies used to construct Fig. 7 might obscure the temporal relationships normally found in nature. For example, Krunic \& Hinks (1972) reported that lower winter storage temperatures reduced the synchrony of emergence when bees were incubated. We also noted that bees maintained outdoors through the winter in an unheated, screened enclosure required more time to eclose than those maintained indoors at $4-5^{\circ} \mathrm{C}$. It is also likely that individuals that overwintered in the screened enclosure experienced somewhat milder temperatures than individuals in natural populations. In natural populations, emergence may be even more extended. Furthermore, individuals in natural populations can be expected to overwinter in nests with varying conditions of aspect, insulation, and protection, all of which would influence the temperature regime experienced and, in turn, the emergence schedule. We suspect that emergence of the spring generation of a natural population would be more platykurtic than that shown in Fig. 7. Any extension of the emergence curve of the spring generation would increase its overlap with the summer generation and the value of $S$.

Another example of potential error is the temperature at which progeny produced by the spring generation were incubated. After collection from field domiciles, bees were maintained at room temperature $\left(24-28^{\circ} \mathrm{C}\right)$ and emergence began at $30 \mathrm{~d}$. This estimate is greater than those of Klostermeyer (1982) and Tasei \& Masure (1978), who reported that emergence of males began at $23 \mathrm{~d}$ at $29^{\circ} \mathrm{C}$. Temperatures in artificial domiciles frequently are much higher than those at which we maintained progeny of the first generation in the laboratory (Undurraga 1978). Thus, the data used to construct Fig. 7 may overestimate by as much as one week the beginning of summer emergence. Shifting the emergence curve of summer generation females 1 wk to the left would further increase intergeneration overlap and increase the estimate of $S$. Conversely, typical temperatures in artificial domiciles such as those measured by Undurraga (1978) are almost certainly higher than those experienced by developing bees in natural situations. As we have no data of the latter, we cannot judge the kind and magnitude of adjustment, if any, that must be made to Fig. 7 . At this point, Fig. 7 must be regarded as a tenuous first attempt to measure $S$.

Data on weights from CL81 suggest that investment patterns in partially bivoltine species such as $M$. rotundata may be quite complicated. The cost of producing offspring varied not only with their sex, but also with the parental generation that produced them and according to whether they diapaused or not (Table 3).

Several interesting questions emerge from these findings: Why do parents of the spring generation produce diapausing offspring that are about $50 \%$ larger than those that develop directly to adults? 
Why are the diapausing individuals produced by the spring generation significantly heavier than those produced by the summer generation? Presumably, the answers to these questions relate to the additional metabolic costs incurred by overwintering individuals that must endure for 9-10 mo as immatures before eclosing. For example, diapausing forms typically build up more food resources than nondiapausing forms (Chapman 1971), and there is much indirect evidence that the metabolic transitions necessary to survive winter temperatures are quite costly (Danks 1978). It is reasonable to suspect that large individuals are better able to survive overwintering than smaller ones. Indeed, in another species of megachilid bee, Osmia lignaria propinqua Cresson, large individuals have a significantly greater chance of overwintering successfully than do small individuals (Tepedino \& Torchio 1982).

Conversely, the advantage of making summeremergent individuals small may be a result of the inverse relationship between size and developmental rate (Rothschild 1979). Because small individuals develop more rapidly, they have more time to produce progeny before the onset of unfavorable fall conditions. In addition, more rapid development by summer-emergent bees would increase the probability that spring males were still available for mating (i.e., higher $S$ ). Because an increase in $S$ decreases the reproductive value of summer-emergent males, spring females would further increase their fitness by producing more females among their summer-emergent progeny.

A second series of questions relates to how the size differences between diapausing and nondiapausing offspring are effected. Offspring size in $M$. rotundata is controlled by the amount of food provided by the female parent (Klostermeyer et al. 1973). In addition, all available evidence supports the hypothesis that diapause is also under maternal control (Bitner 1976, Tasei \& Masure 1978, Parker $\&$ Tepedino 1982). It is possible that female parents control the fate and size of their offspring by the amount of food supplied. Under environmental conditions favorable to the production of emergent offspring (e.g., long photoperiod), females may produce smaller provisions. Offspring reared on small provisions may omit a diapause period either because they develop more rapidly or because of lack of stored food reserves in the fat body. Diapause could be engendered by a subsequent reduction in day length below some threshold that causes females to increase provision size and, thereby, either to extend the developmental period of progeny or to alter their progeny's physiological state by increasing its food reserves.

A related hypothesis is that females are programmed to produce mostly small provisions coupled with nondiapausing eggs upon emergence. The maternal phenotype may then be acted upon by the environment to alter this strategy to one of producing larger provisions together with diapausing eggs. With this mechanism both provision size and fate of progeny are maternally determined. In the previously discussed hypothesis, only provision size is under maternal control and diapause induction is determined solely by the developmental reaction of the offspring to the amount of food supplied. Under both systems, summeremergent bees may be visualized as the progeny produced by females only during their first week of nesting. The production of emergent individuals over a 3 - to 4 -wk span is simply a result of the time period during which females emerge in spring. Another possibility is that the food supply is not controlled maternally, but rather progeny that forego diapause develop more rapidly and less efficiently than those destined to enter diapause. Tasei \& Masure (1978), for example, reported that more rapid development characterized those offspring destined to forego diapause. However, they supplied no information on relative provision size. At present, it is not possible to choose among these hypotheses.

\section{Acknowledgment}

We thank L. Anderson, D. Broemeling, R. Butler, S. Jennings, T. Peery, K. Ruggeri, C. Schmitz, M. Schultz, and D. Veirs for technical assistance; and J. W. Stubblefield for helpful discussions of this work and for providing copies of his unpublished manuscripts. Constructive reviews of the manuscript were offered by J. Cane, D. Frohlich, J. Seger, and J. W. Stubblefield. This paper is a contribution from Utah Agricultural Experiment Station, Utah State University, Logan, journal paper no. 3354, and USDA-ARS Bee Biology and Systematics Laboratory, Utah State University, Logan, Utah.

\section{References Cited}

Bitner, R. M. 1976. Ecological management of the alfalfa leafcutter bee, Megachile pacifica (Panzer), with emphasis on diapause induction. Ph.D. dissertation, Utah State University, Logan.

Chapman, R. F. 1971. The insects. American Elsevier, New York.

Danks, H. V. 1978. Modes of seasonal adaptation in the insects. I. Winter survival. Can. Entomol. 110: $1167-1205$.

Grafen, A. 1986. Split sex ratios and the evolutionary origins of eusociality. J. Theoret. Biol. 122: 95-121.

Johansen, C. A. \& J. D. Eves. 1973. Effects of chilling, humidity, and seasonal conditions on emergence of the alfalfa leafcutting bee. Environ. Entomol. 2: 2326 .

Klostermeyer, E. C. 1982. Biology of the alfalfa leafcutting bee, pp. 10-19. In G. H. Rank [ed.], First International Symposium on Alfalfa Leafcutting Bee Management, University of Saskatchewan Printing Services, Saskatoon, Sask., Canada.

Klostermeyer, E. C., S. J. Mech, Jr., \& W. B. Rasmussen. 1973. Sex and weight of Megachile rotundata (Hymenoptera: Megachilidae) progeny associated with provision weights. J. Kans. Entomol. Soc. 46: 536-548.

Krunic, M. D. 1972. Voltinism in Megachile rotundata (Megachilidae: Hymenoptera) in southern Canada. Can. Entomol. 104: 185-188. 
Krunic, M. D. \& C. F. Hinks. 1972. The effect of temperature and of temperature pretreatment on diapause and on the synchronization of adult emergence in Megachile rotundata (Hymenoptera: Megachilidae). Can. Entomol. 104: 889-893.

McManus, W. R. \& N. N. Youssef. 1984. Life cycle of the chalkbrood fungus, Ascosphaera aggregata, in the alfalfa leafcutting bee, Megachile rotundata, and its associated symptomatology. Mycologia 76: 830842 .

Parker, F. D. 1979. Alfalfa leafcutter bee: origin of female and its influence on diapause. In D. M. Caron [ed.], Proceedings of IVth International Symposium on Pollination. Maryland Agricultural Experiment Station. Special Miscellaneous Publication 1: 269-272.

1985. Effective fungicide treatment for controlling chalkbrood disease (Ascomycetes: Ascosphaeraceae) of the alfalfa leafcutting bee (Hymenoptera: Megachilidae) in the field. J. Econ. Entomol. 78: 35-40.

Parker, F. D. \& V. J. Tepedino. 1982. Maternal influence on diapause in the alfalfa leafcutting bee. Ann. Entomol. Soc. Am. 75: 407-410.

Rank, G. H. \& D. W. Goerzen. 1982. Effect of incubation temperatures on emergence of Megachile rotundata (Hymenoptera: Megachilidae). J. Econ. Entomol. 75: 467-471

Richards, K. W. 1984. Alfalfa leafcutter bee management in Western Canada. Agriculture Canada Publication 1495/E Ottawa

Rothschild, M. 1979. Factors influencing size and sex ratios in Megachile rotundata (Hymenoptera: Megachilidae). J. Kans. Entomol. Soc. 52: 392-401.

Seger, J. 1983. Partial bivoltinism may cause alternating sex-ratio biases that favour eusociality. Nature 301: 59-62.

Stephen, W. P. \& C. E. Osgood. 1965. The induction of emergence in the leaf-cutter bee Megachile rotundata, an important pollinator of alfalfa. J. Econ. Entomol. 58: 284-286.

Stubblefield, J. W. \& E. L. Charnov. 1986. Some conceptual issues in the origin of eusociality. Heredity 57: 181-187.

Tasei, J. N. 1975. Le probleme de l'adaptation de
Megachile (Eutricharea) pacifica Panz. (Megachilidae) Americain en France. Apidologie 6: 1-57.

Tasei, J. N. \& M. M. Masure. 1978. Sur quelques facteurs influencant le développement de Megachile pacifica Panz. (Hymenoptera, Megachilidae). Apidologie 9: 273-290.

Tepedino, V. J. 1983. An open-field test of Megachile rotundata as a potential pollinator of hybrid carrot seed fields. J. Apic. Res. 22: 64-68.

Tepedino, V. J. \& D. R. Frohlich. 1984. Fratricide in Megachile rotundata, a non-social megachilid bee: impartial treatment of sibs and non-sibs. Behav. Ecol. Sociobiol. 15: 19-23.

Tepedino, V. J. \& F. D. Parker. 1986. Effect of rearing temperature on mortality, second-generation emergence, and size of adult in Megachile rotundata (Hymenoptera: Megachilidae). J. Econ. Entomol. 79: 974-977.

Tepedino, V. J. \& P. F. Torchio. 1982. Phenotypic variability in nesting success among Osmia lignaria propinqua females in a glasshouse environment $(\mathrm{Hy}$ menoptera: Megachilidae). Ecol. Entomol. 7: 453462.

Tirgari, S. 1963. The biology and management of the alfalfa-leafcutter bee, Megachile rotundata (Fabr.). M.S. thesis, Utah State University, Logan.

Torchio, P. F. \& V. J. Tepedino. 1980. Sex ratio, body size and seasonality in a solitary bee, Osmia lignaria propinqua Cresson (Hymenoptera: Megachilidae). Evolution 34: 993-1003

Undurraga, J. M. 1978. Effects of temperature and other abiotic and biotic factors on development and survival of the immature stages of the alfalfa leafcutting bee, Megachile pacifica (Panzer) (=rotundata (F.)) (Hymenoptera: Megachilidae). Ph.D. thesis, Oregon State University, Corvallis.

Werren, J. H. \& E. L. Charnov. 1978. Facultative sex ratios and population dynamics. Nature 272: 349 350 .

Received for publication 28 January 1987; accepted 6 January 1988. 